\title{
Contact-free and fast detection of energetic materials in containments
}

\author{
Dominik Wild $^{1, \mathrm{a}}{ }_{(\mathbb{D})}$, Cathrin Theiß ${ }^{2}$, Gerhard Holl ${ }^{1,2}$ \\ ${ }^{1}$ Institute for the Protection of Terrestrial Infrastructures, German Aerospace Center, 53757 St. Augustin, \\ Germany \\ 2 Institute of Detection Technologies, Bonn-Rhein-Sieg University of Applied Sciences, 53359 Rheinbach, \\ Germany
}

Received: 10 January 2021 / Accepted: 9 April 2021

(C) The Author(s) 2021

\begin{abstract}
The identification of energetic materials in containments is an important challenge for analytical methods in the field of safety and security. Opening a package without knowledge of its contents and the resulting hazards is highly involved with risks and should be avoided whenever possible. Therefore, preferable methods work non-destructive with minimal interaction and are capable of identifying target substances in a containment quickly and reliably. Most spectroscopic methods find their limits, if the target substance is shielded by a covering material. To solve this problem, a combined laser drilling method with subsequent identification of the target substance by means of Raman spectroscopic measurements through microscopic bore holes of the covering material is presented. A pulsed laser beam is used for both the drilling process and as an excitation source for Raman measurements in the same optical setup. Results show the ability of this new method to gain high-quality spectra even when performed through microscopic small bore channels. With the laser parameters chosen right, the method can even be performed on highly sensitive explosives like triacetone triperoxide (TATP). Another advantageous effect arises in an observed reduction in unwanted fluorescence signal in the spectral data, resulting from the confocal-like measurement setup with the bore hole acting as aperture.
\end{abstract}

\section{Introduction}

The identification of explosives or hazardous substances concealed in a package is a great challenge for most analytical methods in the field of CBRNE detection. In most cases, improvised explosive devices (IED) are hidden in items of the daily life and generate a high security threat to humans at infrastructures such as airports or train stations in public space. Known techniques can generate a first suspicion for example by detecting small traces on the surface of the object. With the help of imaging methods like x-ray, radar or terahertz radiation, it is possible to provide information on the internal structure [1-5]. Spectroscopic methods like infrared or Raman find their limits, if the target substance is concealed in a

New technologies for detection, protection, decontamination and developments of the decision support systems in case of CBRNe event.

a e-mail: dominik.wild@dlr.de (corresponding author) 
packaging material. Spatial offset Raman spectroscopy (SORS) can provide a good solution for partially transparent polymers and other materials, but cannot be applied in the case of metallic covers [6-9]. Technical solutions for a clarification in such situations and in particular for the identification of unknown substances in containments are urgently needed to decide ongoing steps. Opening a package without knowledge of the contents and its dangerous potential should be avoided whenever possible. Therefore, preferred methods work nondestructive or can be performed with minimal interaction from a safe distance [10-12].

To solve this task, a combined laser drilling method with subsequent identification of the target substance by means of Raman spectroscopic measurements through microscopic small bore holes of the package is presented. Advantages are the non-contact operation of the method, the minimal interaction with the examined object as well as the fast availability of significant results on site without the need for complex laboratory analyses. A pulsed laser source is used for both the laser machining process through the covering material as well as an excitation source for the Raman spectroscopic analysis of the target substance.

\section{Experimental setup}

A schematic view of the setup is displayed in Fig. 1. For the laser drilling process and the Raman measurement, the same laser source and optical setup is used. As laser source, a diode pumped Nd:YAG solid state laser in a master oscillator power amplifier (MOPA) configuration is used. It is equipped with a lithium triborate (LBO) crystal for frequency doubling, resulting in an emission of radiation at $532 \mathrm{~nm}$. Pulse generation is achieved by means of passively q-switching, leading to pulses with durations smaller than $10 \mathrm{~ns}$. The laser is operated in burst mode with a burst repetition rate of $200 \mathrm{~Hz}$ including 10 single pulses in each burst. In addition, an adjustable attenuator based on thin film polarisators is used to variate the pulse energy in a range of $0.04 \mathrm{~mJ}$ up to $3.4 \mathrm{~mJ}$. The system's performance allows percussion drilling into most materials like metals, polymers or textiles with hole diameters in the range of $50 \mu \mathrm{m}$ up to $150 \mu \mathrm{m}$. The penetration depth is high enough to interact with the target substances after the breakthrough of the covering materials is reached.

The laser radiation is focused on the sample by means of a plano-convex and antireflective coated lens with a focal point of $175 \mathrm{~mm}$, which also defines the working distance for the contactless analysis method in this setup. The scattered light coming from the sample is collimated again by the lens and focused into an optical fiber with the help of a silver coated $90^{\circ}$ off-axis parabolic mirror. A center bore hole in the middle of the mirror is intended to transmit the laser beam without losses. The optical fiber is connected to the spectrometer (Ocean Optics Ventana 532). Between the parabolic mirror and the fiber connector, a notch filter is placed to block the backscattered laser light.

The Raman measurements are performed on different energetic substances which are prepared in special sample specimens (ExploTech $\mathrm{GmbH}$ ), allowing reproducible preparation as well as easy decontamination. The specimens provide an inner cylinder with a diameter of $3 \mathrm{~mm}$ and a length of $5 \mathrm{~mm}$, containing the explosive substances. The substances used in this work are triacetone triperoxide (TATP), cyclotrimethylenetrinitramine (RDX), pentaerythritol tetranitrate (PETN) and SEMTEX 1A, a plastic explosive with PETN as main compound. The sample specimens also can be equipped with varied covering materials like different metals and polymers to conceal the explosive material.

Experimental results from previous works show that it is possible even for sensitive explosive substances like TATP or black powder to find suitable laser parameters that will not cause an ignition during the laser process $[13,14]$. Therefore, in this work all analyzed substances 


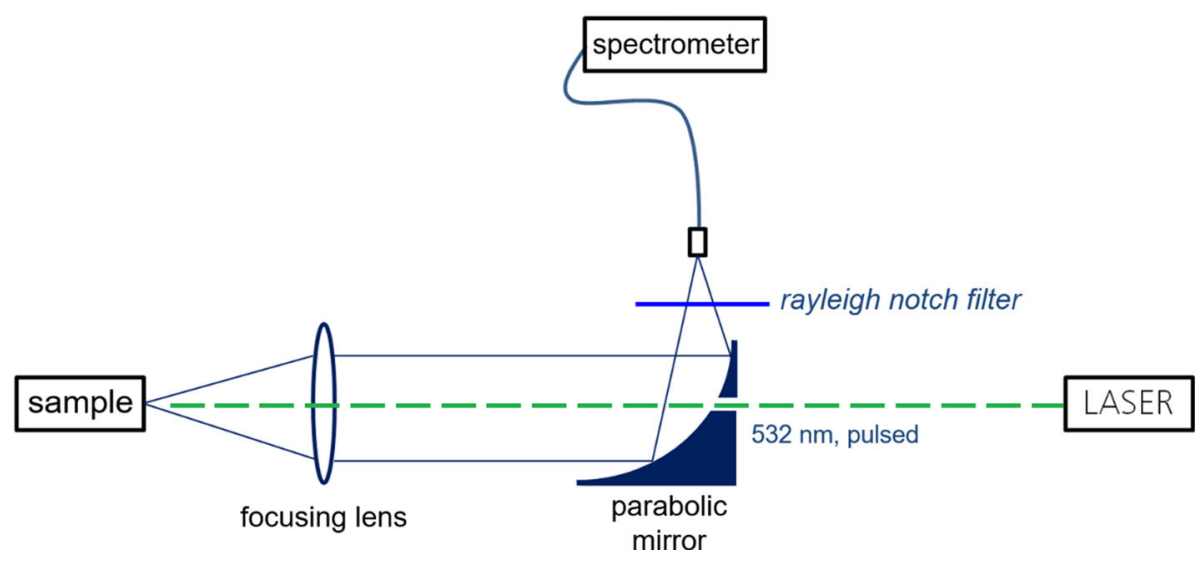

Fig. 1 Experimental setup: A pulsed Nd:YAG laser is used both for the laser drilling process and the Raman excitation. The laser beam is guided through a center bore hole in a parabolic mirror and focused on the sample. The scattered light coming back from the sample is collimated and focused into an optical fiber leading to the spectrometer. A notch filter is used to block the Rayleigh scattered light

were irradiated with laser settings lower than the found limits in order to ensure a safe laser interaction during the experiments.

\section{Experimental results and discussion}

The results show the ability of this new method to gain high-quality spectra even with measurements performed through microscopic small bore channels. With the laser parameters chosen right, the method can even be performed on highly sensitive explosives like triacetone triperoxide (TATP). Figure 2 shows the measured Raman spectra of TATP, first measured through a laser drilled hole in a non-transparent polystyrene cover with the thickness of $0.3 \mathrm{~mm}$ and a hole diameter of approximately $280 \mu \mathrm{m}$. The spectrum is compared with a reference spectrum of an uncovered TATP sample and with a spectrum of the pure polystyrene after a drilling process without TATP. One clearly can see the good accordance of both of the TATP spectra and only a weak influence arising from the covering polymeric material. The Raman spectrum of TATP measured through the laser drilled hole was performed with the given laser parameters after the full penetration of the cover material polystyrene.

In Fig. 3, results of Raman measurements with other energetic materials as target substance are shown in addition to the measurement of TATP. Raman spectra of RDX, PETN and SEMTEX 1A were collected after a laser drilling process in polystyrene. For all substances, qualitatively good spectra could be collected through the covering material. For the spectrum of SEMTEX 1A, a baseline correction was performed. During all performed experiments, atomic emission lines due to plasma radiation were detected only during the drilling process through the covering material. Once the laser drilled bore channel was fully established, no further plasma signal could be recognized in the spectral data. This can be explained due to the lower absorption of the laser radiation in the analyzed substances within the given laser parameters. In the case that any plasma radiation would still be detected after the breakthrough of the covering material, the authors propose a reduction in the laser fluence in order to prevent overlapping spectra being collected from both Raman and plasma effects. 


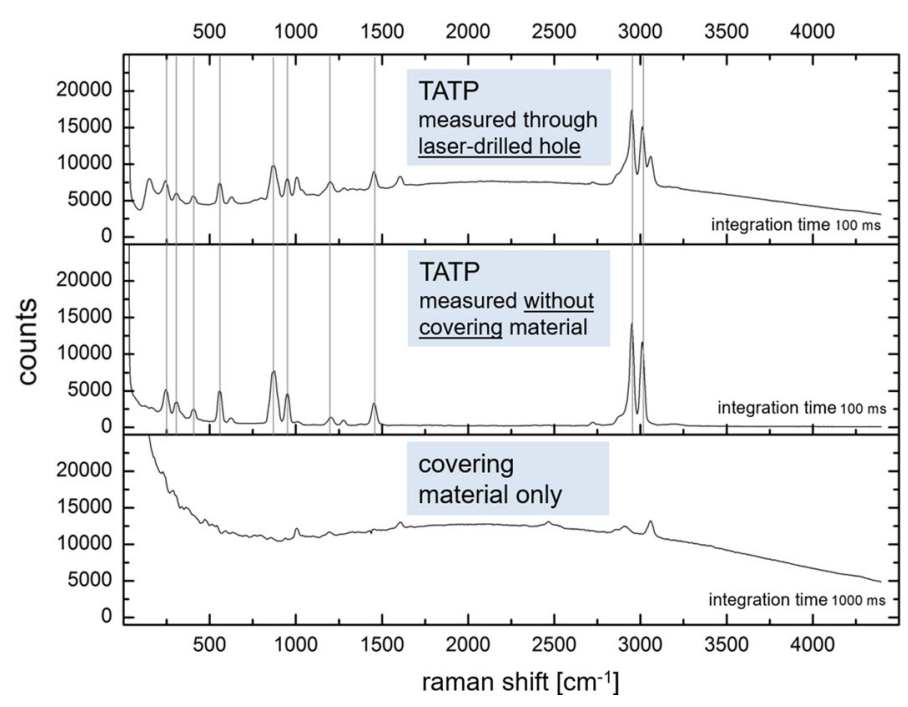

Fig. 2 Raman measurements of the explosive TATP measured through a laser-drilled hole in a 0.3-mm-thick cover of non-transparent polystyrene (top). Raman spectrum of the uncovered TATP as reference (middle). Raman spectrum of the covering material polystyrene (bottom). All measurements were performed with an average laser power of $500 \mathrm{~mW}$ at $532 \mathrm{~nm}$ and an averaging over 5 spectra

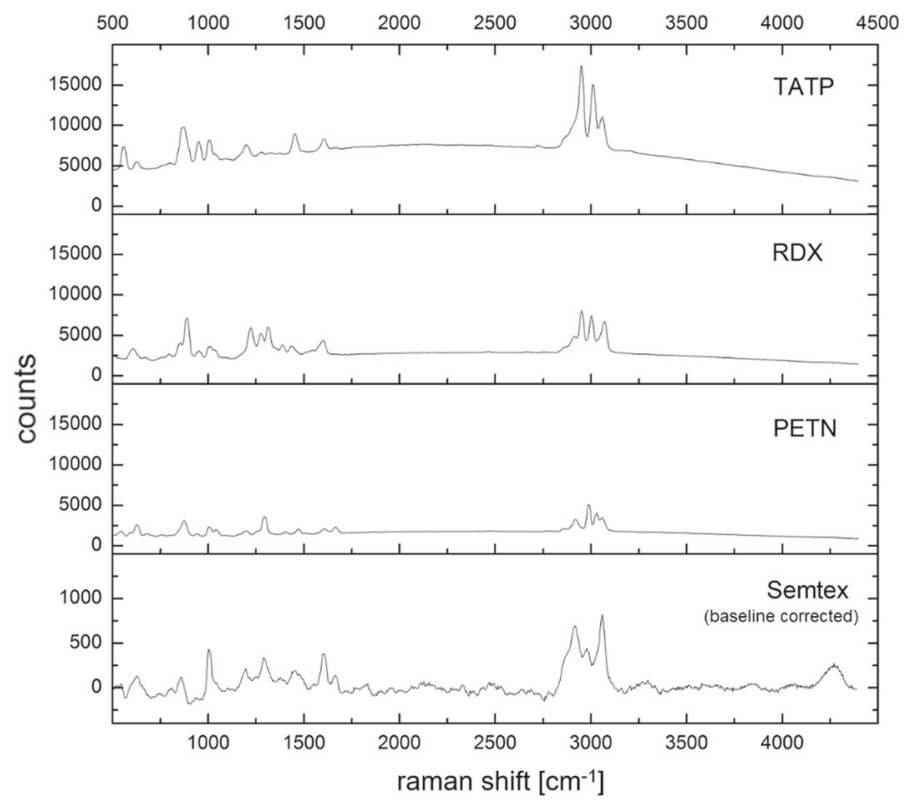

Fig. 3 Raman measurements of TATP, RDX, PETN and SEMTEX 1A measured through a laser-drilled hole in 0.3 -mm-thick polystyrene. The measurements were performed after the full breakthrough of the polystyrene coverage with an average laser power of $500 \mathrm{~mW}$ at $532 \mathrm{~nm}$, an integration time of $100 \mathrm{~ms}$ and an average over 5 spectra

Another advantageous effect is the observed reduction in unwanted fluorescence signal in the spectral data, if the measurement is performed through laser drilled holes with sufficient 


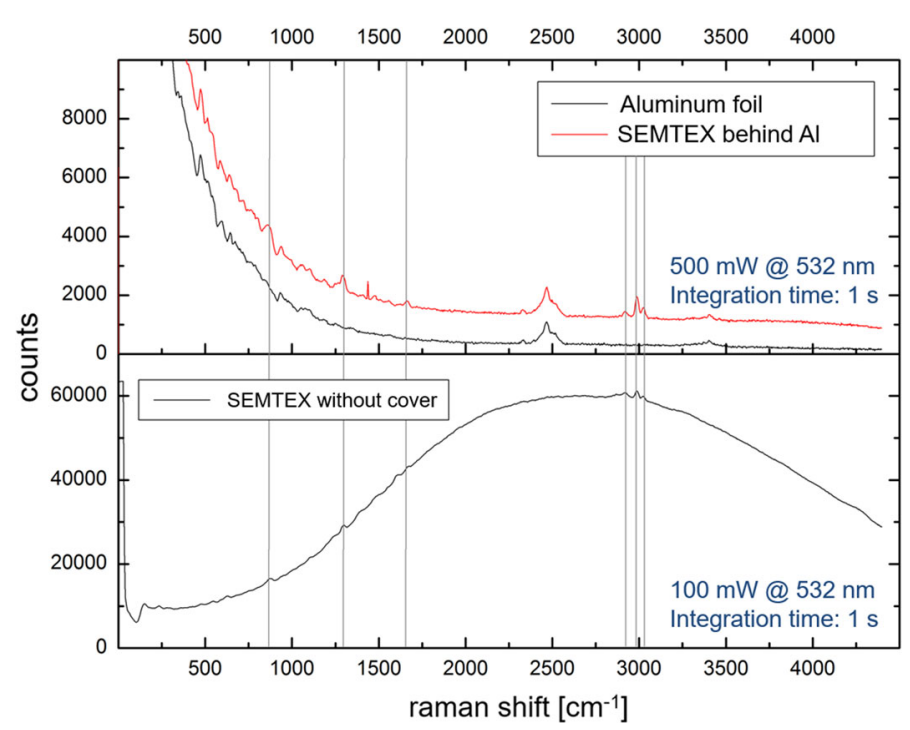

Fig. 4 Fluorescence suppression observed during a Raman measurement of the explosive SEMTEX 1A performed through a laser drilled hole in aluminum foil (top) compared to a Raman measurement of the uncovered SEMTEX 1A (bottom)

small diameters. Figure 4 shows a Raman spectrum of the PETN-based explosive SEMTEX 1A, first measured through a bore hole of aluminum foil with a diameter of $50 \mu \mathrm{m}$ and then measured without any cover. A strong suppression of the fluorescent background can be observed for the measurement that was performed through the bore hole. Most of the Raman lines can be examined more clearly in this analysis. This effect might be explained by a confocal-like behavior of the measurement setup where the laser drilled channel acts as aperture for the measurement.

\section{Summary and outlook}

In the present work, a novel method for the detection of concealed energetic materials was demonstrated. With the help of a laser drilling process, target materials that otherwise would not be detectable by spectroscopic methods can made accessible for Raman measurements. This provides significant information in the elucidation of potentially dangerous situations due to hidden or concealed threats. In particular, the possibility of a Raman spectroscopic analysis through a microscopic drilled channel with simultaneously achieved reduction in interfering fluorescence effects has to be emphasized. The results presented in this paper hold great potential for the future work of security forces for threat assessment of suspicious objects. The use of the technology as a verification method in the case of unclear situations with an initial suspicion can provide a significant contribution for a fast and qualified assessment of the dangerous situation on site from a safe distance and thus provide more security and protection of humans in public spaces and infrastructures.

Next steps will focus on the miniaturization of the detection method for the application in a portable solution for the contact-free and fast identification of unknown hidden substances including sensitive explosives like TATP in a safe manner.

Funding Open Access funding enabled and organized by Projekt DEAL. 
Open Access This article is licensed under a Creative Commons Attribution 4.0 International License, which permits use, sharing, adaptation, distribution and reproduction in any medium or format, as long as you give appropriate credit to the original author(s) and the source, provide a link to the Creative Commons licence, and indicate if changes were made. The images or other third party material in this article are included in the article's Creative Commons licence, unless indicated otherwise in a credit line to the material. If material is not included in the article's Creative Commons licence and your intended use is not permitted by statutory regulation or exceeds the permitted use, you will need to obtain permission directly from the copyright holder. To view a copy of this licence, visit http://creativecommons.org/licenses/by/4.0/.

\section{References}

1. K. Gares, K. Hufziger, S. Bykov, S. Asher, Review of explosive detection methodologies and the emergence of standoff deep UV resonance Raman. J. Raman Spectrosc. 47(1), 124-141 (2016)

2. J.S. Caygill, F. Davis, S.P.J. Higson, Current trends in explosive detection techniques. Talanta 88, 14-29 (2012)

3. S. Wallin, A. Pettersson, H. Östermark, A. Hobro, Laser-based standoff detection of explosives: a critical review. Anal. Bioanal. Chem. 395, 259-274 (2009)

4. K. Wells, D.A. Bradley, A review of x-ray explosives detection techniques for checked baggage. Appl. Radiat. Isot. 70(8), 1729-1746 (2012)

5. M.R. Leahy-Hoppa, M.J. Fitch, R. Osiander, Terahertz spectroscopy techniques for explosives detection. Anal. Bioanal. Chem. 395, 247-257 (2009)

6. B. Zachhuber, C. Gasser, E. Chrysostom, B. Lendl, Stand-off spatial offset raman spectroscopy for the detection of concealed content in distant objects. Anal. Chem. 83(24), 9438-9442 (2011)

7. P. Matousek, I.P. Clark, E.R.C. Draper, M.D. Morris, A.E. Goodship, N. Everall, M. Towrie, W.F. Finney, A.W. Parker, Subsurface probing in diffusely scattering media using spatially offset raman spectroscopy. Appl. Spectrosc. 59, 393-400 (2005)

8. C. Eliasson, N.A. Macleod, P. Matousek, Anal. Chem. 79(21), 8185-8189 (2007). https://doi.org/10.102 $1 / \mathrm{ac} 071383 \mathrm{n}$

9. P. W. Loeffen, G. Maskall, S. Bonthron, M. Bloomfield, C. Tombling, P. Matousek, Chemical and explosives point detection through opaque containers using spatially offset Raman spectroscopy (SORS), in Proc. SPIE 8018, Chemical, Biological, Radiological, Nuclear, and Explosives (CBRNE) Sensing XII, $80181 E(2011)$

10. J.C. Carter, S.M. Angel, M. Lawrence-Snyder, J. Scaffidi, R.E. Whipple, J.G. Reynolds, Standoff detection of high explosive materials at 50 meters in ambient light conditions using a small raman instrument. Appl. Spectrosc. 59, 769-775 (2005)

11. H. Östmark, M. Nordberg, T.E. Carlsson, Stand-off detection of explosives particles by multispectral imaging Raman spectroscopy. Appl. Opt. 50, 5592-5599 (2011)

12. P. Wen, M. Amin, W.D. Herzog, R.R. Kunz, Key challenges and prospects for optical standoff trace detection of explosives. Trends Anal. Chem. 100, 136-144 (2018)

13. D. Wild, C. Theiß, G. Holl, Laser techniques for the assessment of hazardous situations with objects containing chemical and explosive hazardous substances: Final report of the research project LAGEF, Leibniz Information Centre for Science and Technology TIB (2017)

14. D. Wild, L. Pschyklenk, C. Theiß, G. Holl, Remote laser drilling and sampling system for the detection of concealed explosives, in Proc. SPIE 10192, Laser Technology for Defense and Security XIII, 101920J (2017), https://doi.org/10.1117/12.2263752 